\title{
Penjadwalan Ekonomis dan Emisi Pembangkit Listrik Hidro dan Termal dalam Sistem 150 KV di Kalimantan Selatan dan Kalimantan Tengah menggunakan Algoritma Dragonfly
}

\author{
Bayu Setyo Wibowo ${ }^{1}$, Susatyo Handoko ${ }^{2}$, Hermawan ${ }^{3}$ \\ ${ }^{123}$ Program Studi Magister Teknik Elektro, Departemen Teknik Elektro, Universitas Diponegoro, Semarang \\ Jalan Prof. H. Soedarto, Kec. Tembalang, Kota Semarang 50275 \\ 1bayusw93@student. undip.ac.id \\ ${ }^{2}$ susatyo73@gmail. com \\ 3hermawan.60@gmail.com
}

Intisari - Seiring dengan pertumbuhan penduduk dan ekonomi di daerah Kalimantan Selatan kebutuhan listrik menjadi semakin bertambah. Sistem kelistrikan Provinsi Kalimantan Selatan sebagian besar dipasok dari Sistem Barito, Sistem Barito merupakan sistem interkoneksi kelistrikan terbesar di Kalimantan Selatan dengan jaringan transmisi $150 \mathrm{kV}$ dan $70 \mathrm{Kv}$. Sistem tenaga listrik yang baik selain memperhatikan sektor ekonomis dan keandalan, dibutuhkan juga sistem yang memperhatikan dampak terhadap lingkungan karena hal inilah optimasi sistem pembangkit listrik diperlukan untuk dilakukan penjadwalan agar optimal secara ekonomis dalam suatu operasi pembangkitan energi listrik. Pada penelitian ini akan dilakukan penjadwalan ekonomis dan emisi untuk pembangkit listrik hidro dan termal menggunakan bantuan perangkat lunak Matlab 2016. Pada penelitian didapatkan hasil dari simulasi Dragonfly Algorithm menunjukkan bahwa faktor pembobotan berpengaruh kepada biaya pembangkitan. Jika faktor pembobotan lebih diprioritaskan pada faktor ekonomis, maka biaya pembangkitan akan murah, namun memiliki nilai emisi yang tinggi, begitu pula sebaliknya.

Kata kunci - Sistem Barito, Sistem tenaga listrik, Pembangkit Hidro dan pembangkit Termal, Dragonfly Algorithm.

Abstract - Along with population and economic growth in the South Kalimantan area, the demand for electricity is increasing. The electricity system of South Kalimantan Province is mostly supplied from the Barito System. The Barito System is the largest electricity interconnection system in South Kalimantan with $150 \mathrm{kV}$ and $70 \mathrm{Kv}$ transmission networks. In addition to paying attention to the economical and reliability sectors, a good electric power system is also needed to pay attention to the impact on the environment because this is why the optimization of the power generation system is needed for scheduling to be economically optimal in an operation of generating electrical energy. In this research, economical and emission scheduling will be carried out for hydro and thermal power plants using the help of the Matlab 2016 software. In this research, the results of the Dragonfly Algorithm simulation show that the weighting factor affects the cost of generation. If the weighting factor is prioritized on economic factors, the generation cost will be cheap, but it will have a high emission value.

Keywords - Barito system, Electric power system, Hydro and thermal generator, Dragonfly Algorithm.

\section{PENDAHULUAN}

Seiring dengan pertumbuhan penduduk dan ekonomi di daerah Kalimantan Selatan kebutuhan listrik menjadi semakin bertambah. Sistem kelistrikan Provinsi Kalimantan Selatan sebagian besar dipasok dari Sistem Barito, Sistem Barito merupakan sistem interkoneksi kelistrikan terbesar di Kalimantan Selatan dengan jaringan transmisi $150 \mathrm{kV}$ dan $70 \mathrm{kV}$. [1]

Konsumsi energi listrik di Provinsi Kalimantan Selatan tahun 2018 mencapai sekitar 4.058 GWh dengan komposisi konsumsi per sektor pemakai didominasi oleh sektor rumah tangga sekitar $2.046 \mathrm{GWh}$ (50\%), industri sekitar 1.172 GWh (29\%), bisnis sekitar 564 GWh (14\%), dan publik sekitar 275 GWh (7\%). Hal tersebut menuntut PLN (Perusahaan Listrik Negara ) untuk menjaga kontinutias penyaluran daya pada sistem kelistrikan secara aman dan murah serta memaksimalkan pemikul beban dasar dan penjaga stabilitas sistem perlu dilakukannya optimasi. Saat ini komponen biaya pokok produksi yang terbesar adalah 
biaya bahan bakar, dan pada saat ini konsumsi energi listrik telah mengalami pertumbuhan pesat. PLN pun terus berupaya untuk mensubtitusi penggunaan bahan bakar mahal ke bahan bakar murah dengan cara melakukan penjadwalan. [2]

Pada sistem tenaga listrik yang terhubung dalam suatu interkoneksi, unit-unit pembangkit tidak berada dalam jarak yang sama dengan pusat beban. Selain itu, biaya pembangkitan masing-masing unit pembangkit juga berbeda. Dalam kondisi operasi normal sekalipun, kapasitas yang dimiliki oleh sistem pembangkitan harus lebih besar dibanding jumlah kebutuhan beban dan rugi-rugi daya pada sistem. Sistem tenaga listrik yang baik selain memperhatikan sektor ekonomis dan keandalan, dibutuhkan juga sistem yang memperhatikan dampak terhadap lingkungan.

Pada saat ini penjadwalan pembangkitan hidrotermal dengan cara yang paling ekonomis merupakan hal penting dalam sistem tenaga modern untuk memenuhi kebutuhan dalam pasar energi. Biaya total operasi ini diwakili oleh biaya pembangkitan termal selama waktu optimisasi. Unit pembangkit dengan biaya operasi paling murah dioperasikan untuk memikul beban dasar dari sistem, khususnya unit pembangkit hidro. Selanjutnya unit pembangkit thermal dengan biaya operasi yang lebih mahal dioperasikan untuk memenuhi kebutuhan beban yang tersisa.[3]

Pembangkit listrik tenaga termal adalah sumber utama karbon dioksida (CO2), sulfur dioksida (SO2), dan nitrogen oksida (NOx) yang menyebabkan polusi atmosfer [4]. Apalagi efisiensi energi dan jumlah emisi yang dilepaskan ke udara dari pembangkit listrik termal memiliki hubungan timbal balik yang berarti jika efisiensi ditingkatkan emisi polusi yang dihasilkan juga akan berkurang.

Oleh karena itu, penjadwalan hidrotermal jangka pendek dapat diperluas untuk meminimalkan emisi gas yang mengakibatkan kerusakan lingkungan barubaru ini dengan persyaratan selain minimalisasi biaya bahan bakar pembangkit listrik termal juga membentuk gabungan penjadwalan jangka pendek hidrotermal emisi ekonomi [5]. Terdapat banyak metode yang dipakai untuk mencari solusi masalah penjadwalan hidro termal, optimasi tersebut secara umum dapat digolongkan menjadi dua kelompok, metode deterministik dan metode heuristik..

Pada penelitian ini penulis akan menerapkan Dragonfly Algorithm sebagai penjadwalan jangka pendek hidrotermal dengan tujuan memaksimalkan pembangkitan hidro sehingga dapat meminimalkan biaya pembangkitan termal dan memecahkan pokok permasalahan economic dan emisi dispatch

\section{KAJIAN PUSTAKA}

\section{A. Sistem Tenaga Listrik}

Sistem tenaga listrik adalah suatu sistem yang berfungsi untuk membangkitkan, mentrasmisikan, dan mendistribusikan energi listrik dari pusat pembangkit sampai konsumen. [35]

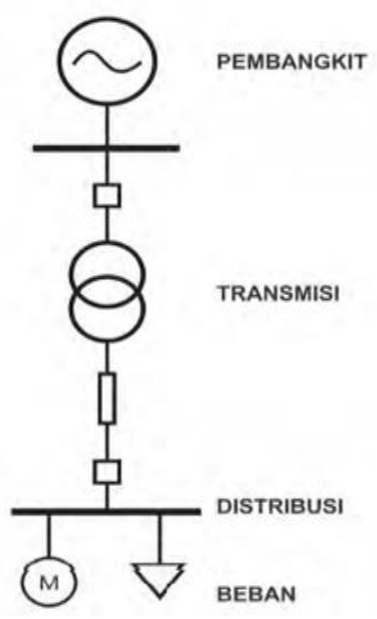

Gbr.1. Sistem Tenaga Listrik

\section{B. Karakteristik Unit Pembangkit}

Secara umum jenis - jenis posisi pembangkit dalam sistem adalah pembangkit pemikul beban dasar (base load), pemikul beban menengah (load follower) dan pemikul beban puncak (peaker).

1) Karakteristik Input-output Pembangkit Termal

Secara umum karakteristik input-output pembangkit termal berbentuk Btu per hour input ke unit generator $(M B t u / h)$. 
Biaya pembangkitan adalah perkalian dari biaya (\$) kalori yang terkandung dalam bahan bakar dengan kebutuhan kalori tiap jam dari generator $(B t u / h)$. Hasil daya yang dibangkitkan (Mega Watt) direpresentasikan dengan $\mathrm{P}_{\mathrm{G}}$. [6]

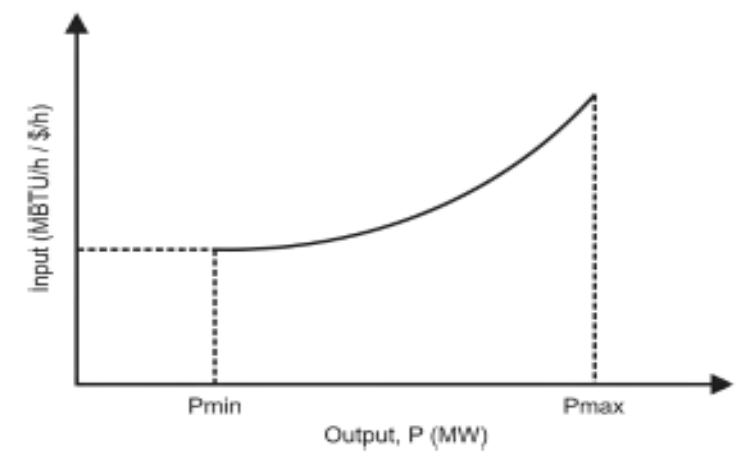

Gbr.2 Kurva Input-Output Pembangkit Termal (ideal)

Karakteristik ini memperlihatkan hubungan antara input pembangkit sebagai fungsi dari output pembangkit. Persamaan karakteristik input-output pembangkit menyatakan hubungan antara jumlah bahan bakar yang dibutuhkan untuk menghasilkan daya tertentu pada pembangkit listrik yang didekati dengan fungsi binomial, yaitu :[36]

$$
(\mathrm{F})=a P 2+b P+c
$$

Keterangan :

$\mathrm{F}=$ Biaya bahan bakar per jam (Rp/jam)

$\mathrm{P}=$ Output daya pembangkit (MW)

$\mathrm{a}, \mathrm{b}, \mathrm{c}=$ Konstanta persamaan

\section{2) Karakteristik Input-output Pembangkit} Hidro

Karakteristik input-output dari pembangkit tenaga listrik hidro menggambarkan hubungan antara input ke penggerak mula (turbin) berupa jumlah air yang dialirkan diantara sudu-sudu turbin persamaan waktu dengan output daya dari generator. Output dari pembangkit listrik hidro adalah daya yang dikirim keluar. [36]

\section{Optimasi Pembangkit Listrik}

Pembagian beban pembangkit dalam suatu operasi sistem tenaga listrik merupakan hal yang penting untuk mencapai suatu operasi yang optimal. Diperlukan koordinasi dalam penjadwalan pembebanan besar daya listrik yang dibangkitkan masing-masing pusat pembangkit listrik, sehingga diperoleh biaya pembangkit yang minimum.[7]

1) Penjadwalan Ekonomis (Economic Dispatch)

Penjadwalan ekonomis merupakan suatu usaha untuk menentukan besar daya yang harus disuplai dari tiap unit generator untuk memenuhi beban tertentu dengan cara membagi beban tersebut pada unit-unit pembangkit yang ada dalam sistem secara optimal ekonomis dengan tujuan meminimumkan biaya operasi pembangkitan.[8]

\section{2) Penjadwalan Jangka Pendek Hidrotermal}

Penjadwalan hidrotermal tujuan utamanya adalah untuk memenuhi permintaan sistem dan sekaligus memenuhi persyaratan sistem lainnya dengan menyebarkan produksinya di antara pembangkit listrik hidro (HPP) dan pembangkit listrik tenaga panas (TPP).[5]

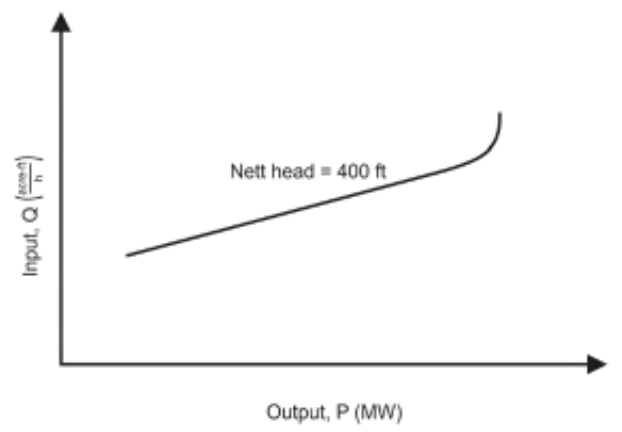

Gbr.3 Kurva Input-Output Pembangkit Hidro (ideal)

\section{Combined Economic and Emission Dispatch}

Pengiriman ekonomi dan pengiriman emisi adalah optimalisasi dengan tujuan masalah emisi yang terabaikan dalam pengiriman ekonomi dan tujuan biaya bahan bakar tidak dipertimbangkan dalam masalah pengiriman emisi.[4]

$$
\begin{aligned}
& \text { Min Objective }=w 1 \times F 1\left(P_{\text {si,m }}\right)+ \\
& w 2 \times \operatorname{PRm} \times F 1\left(P_{s i, m}\right)
\end{aligned}
$$

w1 : weight factor associate with fuel cost objective

w2 : weight factor associate with emission objective

F1 : fuel cost objective 
F2 : Emission objective

$\mathrm{P}_{\mathrm{si}, \mathrm{m}}$ : power output of thermal unit $i$ at subinterval $m$

$\mathrm{P}_{\mathrm{Rm}}$ : price penalty factor during subinterval $m$

\section{E. Sistem Kelistrikan Kalimantan Selatan} dan Kalimantan Tengah

Sistem Kalseltengtimra mulai terbentuk tahun 2019 yang meliputi 4 Provinsi yaitu Kalimantan Selatan, Kalimantan Tengah, Kalimantan Timur, dan Kalimantan Utara. Kemudian mulai tahun 2020 Sistem Kalseltengtimra akan terhubung dengan Sistem Kalbar membentuk Sistem Kalimantan. [9]

Sistem Interkoneksi Kalimantan Selatan dan Kalimantan Tengah disebut sebagai sistem Barito yang tersistem isolasi terpencar yang ditenagai pembangkit diesel yang merupakan sistem interkoneksi yang terhubung melalui jaringan SUTT $150 \mathrm{kV}$ saluran udara tegangan tinggi $150 \mathrm{kV}$ dan 70 $\mathrm{kV}$. Sistem Barito saat ini disuplai dari PLTU AsamAsam, PLTD Trisakti, PLTA Ir. PM Noor, ExcessPower, dan beberapa unit pembangkit termal dengan bahan bakar minyak.[1]

\section{F. Dragonfly Algoritma}

Tujuan utama dari algoritma Dragonfly dimulai dengan statis sebagai titik awal dan kerumunan energik perilaku capung. Kedua perilaku mengerumuni itu terlihat serupa di kedua tahap utama dalam pengoptimalan melalui meta algoritma heuristik, yaitu investigasi dan pemanfaatan.[10]

Perilaku ini diwakili oleh model matematika berikut menggunakan Persamaan. (3) - (7).

1) Perilaku Pemisahan:

$$
S_{i}=\sum_{j=1}^{N} X-X_{j}
$$

2) Perilaku menjaga penerbangan terkoordinasi dengan kelompok capung:

$$
A_{i}=\frac{\sum_{j=1}^{N} V_{j}}{N}
$$

3) Perilaku mendekat satu sama lain untuk setiap individu (Kohesi):

$$
C_{i}=\frac{\sum_{j=1}^{N} X_{j}}{N}-X
$$

4) Perilaku mencari makan:

$$
F_{i}=X^{+}-X
$$

5) Perilaku menghindari musuh:

$$
E_{i}=X+X^{-}
$$

\section{METODE PENELITIAN}

Berikut merupakan diagram alir dari penelitian dan program yang penulis lakukan:

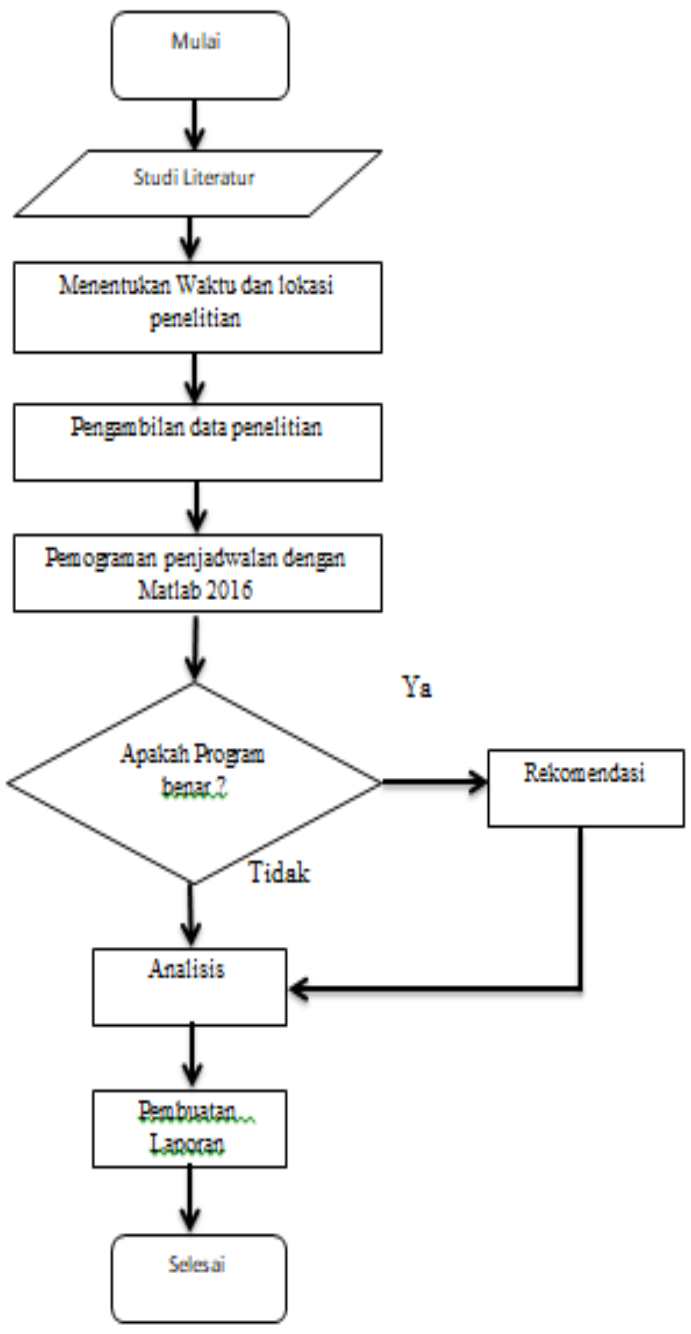

Gbr.4. Flowchart Alur Penelitian 


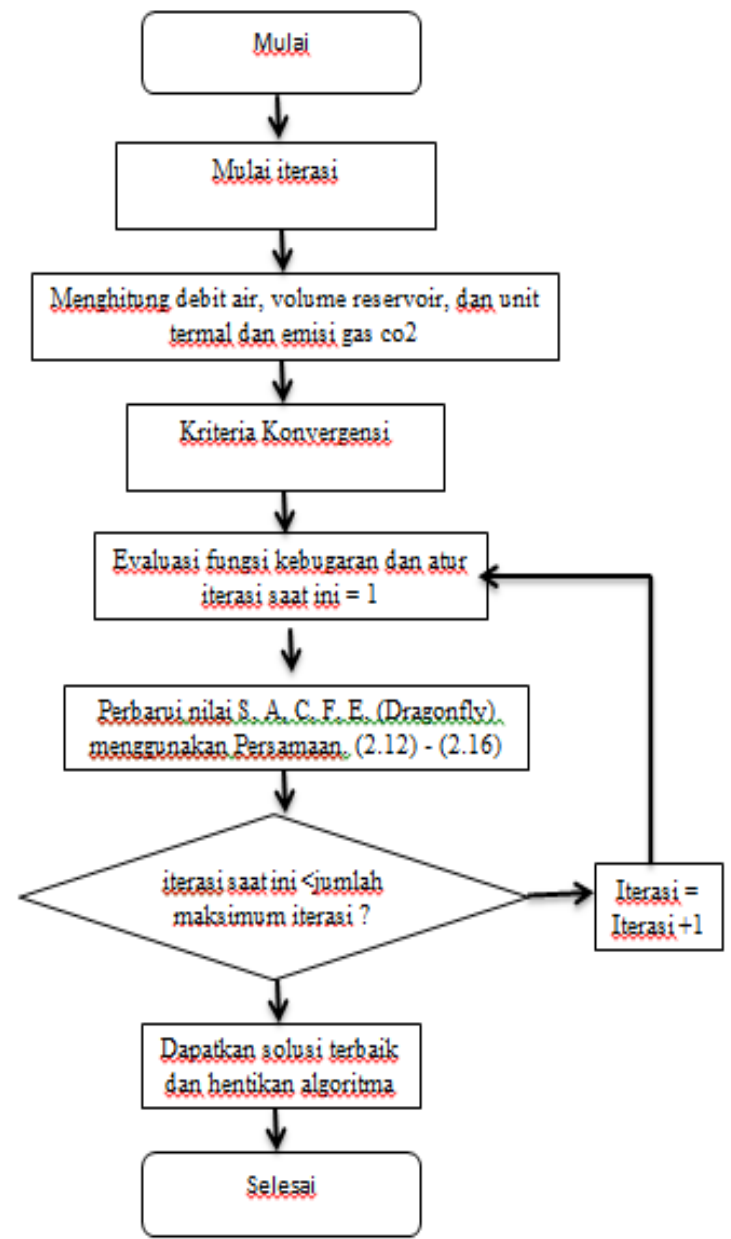

Gbr.5. Flowchart Dragonfly Algorithm

\section{HASIL DAN PEMBAHASAN}

\section{A. Pengujian Metode Dragonfly Algorithm}

Sebelum diterapkan pada sistem $150 \mathrm{kV}$ Kalimantan Selatan dan Kalimantan Tengah , terlebih dahulu akan dilakukan pengujian terhadap metode yang akan digunakan. Metode yang digunakan akan dibandingkan dengan metode penjadwalan ekonomis metode iterasi lamda. Pengujian ini dilakukan dengan menggunakan plant yang terdiri dari 5 pembangkit dan akan dilakukan tanpa mempertimbangkan emisi dan dengan mempertimbangkan emisi.

1) Pengujian Tanpa Mempertimbangkan

Emisi

Percobaan dilakukan selama 5 kali dan menggunakan beban sebesar $320 \mathrm{MW}$. Tabel 1 Perbandingan Biaya Pembangkitan Tanpa Mempertimbangkan Emisi
Tabel 1. Perbandingan Biaya Pembangkitan Tanpa Mempertimbangkan Emisi

\begin{tabular}{|c|cc|cc|}
\hline NO & \multicolumn{2}{|c|}{$\begin{array}{c}\text { Algoritma } \\
\text { Dragonfly }\end{array}$} & \multicolumn{2}{c|}{$\begin{array}{c}\text { Metode Iterasi } \\
\text { Lamda }\end{array}$} \\
\hline 1 & $\mathrm{Rp}$ & 167.927 .206 & $\mathrm{Rp}$ & 167.969 .188 \\
\hline 2 & $\mathrm{Rp}$ & 174.470 .095 & $\mathrm{Rp}$ & 174.513 .713 \\
\hline 3 & $\mathrm{Rp}$ & 165.756 .426 & $\mathrm{Rp}$ & 165.797 .865 \\
\hline 4 & $\mathrm{Rp}$ & 170.819 .341 & $\mathrm{Rp}$ & 170.862 .046 \\
\hline 5 & $\mathrm{Rp}$ & 164.151 .106 & $\mathrm{Rp}$ & 164.192 .144 \\
\hline $\begin{array}{l}\text { Nilai } \\
\text { Rata- } \\
\text { rata }\end{array}$ & $\mathrm{Rp}$ & 168.624 .835 & $\mathrm{Rp}$ & 168.666 .991 \\
\hline
\end{tabular}

Berdasarkan data pada tabel 1, diketahui bahwa biaya optimal dari kedua metode berbeda. Pada metode Algortima Dragonfly, setelah dilakukan percobaan selama 5 kali didapatkan rata-rata biaya pembangkitan sebesar Rp 167.927.206 Sedangkan pada Metode Iterasi Lamda didapatkan total biaya pembangkitan sebesar Rp 167.969.188. Terlihat bahwa metode Algortima Dragonfly melakukan optimasi biaya pembangkitan dengan rata-rata sebesar $\mathrm{Rp}$ 42.156. Selanjutnya akan dilakukan pengujian dengan mempertimbangkan emisi.

2) Pengujian Dengan Mempertimbangkan Emisi

Percobaan dilakukan selama 5 kali dan menggunakan beban sebesar 400 MW. Pengujian dilakukan dengan menggunakan faktor pembobotan $\mathrm{W} 1=0.5$ dan $\mathrm{W} 2=0.5$

Tabel 2. Perbandingan Biaya Pembangkitan Dengan Mempertimbangkan Emisi

\begin{tabular}{|c|c|c|c|c|}
\hline \multirow[b]{2}{*}{ NO } & \multicolumn{2}{|c|}{ Metode Dragonfly } & \multicolumn{2}{|c|}{ Metode Iterasi Lamda } \\
\hline & $\begin{array}{c}\text { Biaya Konsumsi } \\
\text { Bahan Bakar (Rp) } \\
\text { Dengan Emisi }\end{array}$ & $\underset{\text { ton }}{\text { Emisi Per }}$ & $\begin{array}{c}\text { Biaya Konsumsi } \\
\text { Bahan Bakar (Rp) } \\
\text { Dengan Emisi }\end{array}$ & $\begin{array}{c}\text { Emisis Per } \\
\text { ton }\end{array}$ \\
\hline 1 & Rp151.398.354 & 915,22 & Rp151.436.204 & 917,51 \\
\hline 2 & Rp154.247.570 & 936,28 & Rp154.286.132 & 936,51 \\
\hline 3 & Rpl48.129.253 & 909,95 & Rp148.166.286 & 910,18 \\
\hline 4 & Rp153.527.768 & 927,34 & Rp153.566.150 & 927,57 \\
\hline 5 & Rpl48.519.146 & 898,22 & Rp148.556.276 & 898,45 \\
\hline Rata- & Rpp151.164.418 & 917,40 & Rpp151.202.209 & 918,044 \\
\hline
\end{tabular}

Berdasarkan data pada tabel 2, diketahui bahwa biaya optimal dari kedua metode berbeda. Setelah dilakukan 5 kali percobaan, 
diketahui bahwa biaya optimal rata-rata yang dihasilkan oleh metode Algoritma Dragonfly adalah Rp151.164.418 per hari dengan emisi sebesar 917,40 ton per hari. Sedangkan biaya optimal rata-rata yang dihasilkan oleh metode Iterasi Lamda adalah Rp151.202.209 per hari dengan emisi sebesar 918,044 ton per hari. Dari 2 jenis pengujian yang telah dilakukan,terlihat bahwa metode yang diusulkan dapat menghasilkan optimasi pada biaya sebesar Rp37.791 dan emisi sebesar 0,641 ton.

\section{B. Hasil Simulasi}

Simulasi dilakukan dengan Algoritma Dragonfly menggunakan parameter Jumlah Agent, Jumlah Iterasi dan Beban Simulasi akan dilakukan sebanyak 5 kali percobaan. Pada simulasi, nilai W1 dan W2 ditetapakan sebagai bobot dapat dilihat pada tabel 3

Tabel 3. Nilai Pembobotan Untuk Simulasi

\begin{tabular}{|c|c|c|}
\hline Kasus & W1 & W2 \\
\hline 1 & 1 & 0 \\
\hline 2 & 0,75 & 0,25 \\
\hline 3 & 0,5 & 0,5 \\
\hline 4 & 0,25 & 0,75 \\
\hline 5 & 0 & 1 \\
\hline
\end{tabular}

Pada saat kasus 1 , nilai pembobotan lebih tepatkan pada faktor ekonomis memprioritaskan pereduksian kuantitas kuantitas. Pada saat kasus 3, nilaipembobotan bernilai seimbang, artinya biaya pembangkitan dan pengurangan kuantitas kuantitas sama-sama diprioritaskan. Sedangkan pada saat kasus 5,nilai pembobotan lebih tertarikkan pada hari emisi perjanjian mementingkan faktor ekonomis. Hasil simulasi untuk berbagai jenis kasus dan beban, dapat dilihat pada tabel 4

Tabel 4. Total Biaya dan Emisi

\begin{tabular}{|r|lr|c|}
\hline Kasus & \multicolumn{2}{|c|}{$\begin{array}{c}\text { Biaya Konsumsi Bahan } \\
\text { Bakar (Rp) Dengan Emisi }\end{array}$} & Emisi Per ton \\
\hline 1 & $\mathrm{Rp}$ & 302.796 .708 & 915 \\
\hline 2 & $\mathrm{Rp}$ & 264.947 .120 & 1144 \\
\hline 3 & $\mathrm{Rp}$ & 227.097 .531 & 1373 \\
\hline 4 & $\mathrm{Rp}$ & 189.247 .943 & 1602 \\
\hline 5 & $\mathrm{Rp}$ & 151.398 .354 & 1830 \\
\hline
\end{tabular}

Pada tabel 4 dapat dilihat jika nilai pembobotan W1 dan W2 akan berpengaruh pada biaya pembangkitan dan emisi yang dihasilkan. Jika nilai W1 lebih kecil dan nilai W2 semakin besar, maka biaya pembangkitan akan semakin besar, namun emisi yang dihasilkan akan semakin kecil, sebaliknya jika nilai $\mathrm{W} 1$ semakin besar dan nilai W2 semakin kecil, maka biaya pembangkitan akan semakin kecil namun emisi yang dihasilkan akan semakin besar. Grafik hubungan antara biaya pembangkitan dan emisi dapat dilihat pada gambar 5 .

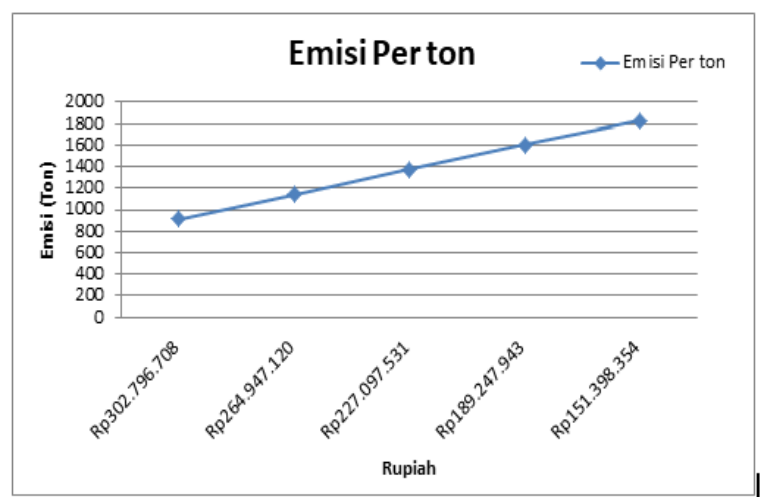

Gbr.5 Grafik Hubungan Biaya Pembangkitan dan Emisi

\section{KESIMPULAN}

Berdasarkan hasil yang didapatkan dari simulasi dan analisis pada penelitian ini, maka didapat kesimpulan sebagai berikut:

1. Besar biaya pembangkitan tergantung pada biaya fungsi ekonimi dan fungsi emisi.

2. Hasil dari simulasi Algoritma Dragonfly menunjukkan bahwa faktor pembobotan berpengaruh kepada biaya pembangkitan. Jika faktor pembobotan lebih diprioritaskan pada faktor ekonomis, maka biaya pembangkitan akan murah, namun memiliki nilai emisi yang tinggi, begitu pula sebaliknya. 


\section{REFERENSI}

[1] C. Widyastuti, H. Suyanto, and D. R. Febrianini, "Analisa Interkoneksi Sistem Menggunakan DigSilent," vol. 5, no. 1, pp. 24-31, 2015.

[2] R. Abdullah and M. Dachyar, "Optimalisasi Pembebanan Pembangkit Pada Sistem 500 kV Jawa Bali Dengan Menggunakan Cuckoo Search Algorithm," pp. 2-3, 2019.

[3] S. Rahmat, A. G. Abdullah, and Hasbullah, "Koordinasi Hidro Thermal Unit Pembangkitan Jawa-bali menggunakan Metode Dynamic Programming," Electrans, Vol 13 no 2, vol. 444, no. 2, pp. 167-180, 2014.

[4] T. T. Nguyen and D. N. Vo, "An efficient cuckoo bird inspired metaheuristic algorithm for short-term combined economic emission hydrothermal scheduling," Ain Shams Eng. J., vol. 9, no. 4, pp. 483-497, 2018, doi: 10.1016/j.asej.2016.04.003.

[5] A. Glotić and A. Zamuda, "Short-term combined economic and emission hydrothermal optimization by surrogate differential evolution," Appl. Energy, vol. 141, pp. 42-56, 2015, doi: 10.1016/j.apenergy.2014.12.020.
[6] H. Saadat, "Power System Analysis." McGraw-Hill, 1999.

[7] D. A. Pratama, O. Penangsang, and N. K. Aryani, "Economic and Emission Dispatch Pada Sistem Transmisi Jawa Bali $500 \mathrm{kV}$ Berdasarkan RUPTL 2015-2024 Menggunakan Modified Artificial Bee Colony Algorithm," $J$. Tek. ITS, vol. 5, no. 2, 2017, doi: 10.12962/j23373539.v5i2.16233.

[8] N. K. A. yani Bobby Prayogo, rony setyo wibowo, "Koordinasi Jangka Pendek Pembangkit Hydrothermal menggunakan Firefly algoritm," Tek. Its, 2016.

[9] PLN, "Perspektif Pengembangan Sistem Ketenagalistrikan Kalimantan Disampaikan Pada: Skema Pembangunan Infrastruktur Ketenagalistrikan ( PIK )," 2015.

[10] C. Shilaja and T. Arunprasath, "Internet of medical things-load optimization of power flow based on hybrid enhanced grey wolf optimization and dragonfly algorithm," Futur. Gener. Comput. Syst., vol. 98, pp. 319-330, 2019, doi: 10.1016/j.future.2018.12.070. 